\title{
The Emergence of Kleptomania in Children and How to Cope with Therapy
}

\author{
Birnabas Buzsik $^{1}$, Klainheisler Foila ${ }^{1}$ \\ ${ }^{1}$ Social Science Department, Corvinus University of Budapest, Hungary
}

\begin{abstract}
The risks of kleptomania in children are discussed, as well as influences that influence kleptomania in children, signs and triggers of kleptomania in children, and Overcoming Kleptomania in Children. Since committing fraud, the kid would, on the whole, feel satisfied. Kleptomania is often linked to depression or obsessive-compulsive behavior. Kleptomaniacs steal on the spur of the moment, with little prior planning. Kleptomania is caused by a chemical imbalance in the brain that occurs during a head injury. Several approaches to overcoming kleptomania in children can be used, including parental approaches, Islamic approaches, talking to a psychiatrist, giving the child love and encouragement, including the child in athletic activity, psychotherapy and Rational Emotive Counseling, and opioid rehab against the child to discourage the offender from being more serious.
\end{abstract}

Keywords: Kleptomania, Obsessive-Compulsive Disorder \& Chemicals in the Brain

Received: January 7, 2021

Revised: February 14, 2021

Accepted: February 26, 2021

\section{Introduction}

Since he is often scared and seen as a poor guy, this behavioral condition can have an effect on the perpetrator's social life. Kleptomania is an impulsive control condition in which a person can't stop himself from stealing or shoplifting (Urso et al., 2018; Wiedemann, 1998). This is a mental condition and it cannot often be monitored, particularly though the suspect is aware that theft is bad. Kleptomania affects people of all ages, from infants to adults. Kleptomania may arise in old age in extreme circumstances (Fishbain, 1987; Sarasalo et al., 1997). Kleptomania is a disorder that affects children and adults. It is described as the inability to suppress repetitive urges to steal things that are not necessarily required for personal use or that are stolen for reasons other than monetary benefit. Kleptomania is described as the inability to suppress the desire to steal objects that are not either required for personal use or lost, regardless of whether the products are costly or not. An individual with kleptomania steals not to meet his own personal needs or to meet his everyday needs, but as a show of confidence in himself and to satisfy the complacency that governs his mind, such that after stealing, he can simply throw away his stolen goods or offer them as a gift to someone as though they were his own. Any facts regarding kleptomania sufferers include having extreme desires to rob other people's possessions, experiencing intense turmoil while trying to steal, experiencing pleasure when stealing, and experiencing remorse and shame after stealing. Islamic advice and counselling is one of the therapies. Kleptomania is a neurological illness in which sufferers struggle to suppress their urges to rob. Kleptomaniacs also steal items that they do not need. Kleptomaniacs steal on the spur of the moment, with little prior planning. Unlike other robbers who schedule their heists ahead of the time.

\section{Kleptomania Factors}

Kleptomania is also linked to depression and obsessive-compulsive disorder. Excessive fatigue, a traumatic brain accident, possessing kleptomania siblings, mood disturbances, 
addictions, and obsessive-compulsive disorder are all contributing factors that may improve kleptomania conduct. Kleptomania affects people who are unable to restrain their impulses to rob. As a result, the sufferer does not steal with a plan in mind, but rather as a habit and the result of a state that compels him to steal. And he can't seem to suppress the overwhelming temptation to steal. And if the item he took was useless, the crime was carried out due to a pathological insistence that it could not be controlled, and this was a psychiatric condition known as obsession-compulsion neurosis.

\section{Symptoms and causes of Kleptomania in children}

There will be anxiety in the kid until he takes objects that do not belong to him. The child will be relieved and satisfied after picking up the products. The most of the time, children perform so alone and with caution enough that no one else notices. Shame, remorse, and anxiety are all emotions that kleptomaniac children encounter.

Furthermore, kleptomania is characterized by a sense of accomplishment after committing robbery. Kleptomania is a condition that occurs while maniacs or antisocial personal problems are presented.

According to Sulthana et al. (2015) many individuals are unaware of any of the features of kleptomania, such as stealing for the sake of reinforcement rather than the value of the goods. Unlike theft, kleptomania is committed by an individual to satisfy his compulsion to seize other people's belongings. In fact, the stolen goods aren't always useful to him. The temptation to rob is uncontrollable once it starts. Sufferers also experience elevated levels of anxiety prior to taking medications. Theft also happens on the spur of the moment. Since doing fraud, there is a sense of accomplishment. Sufferers have the option of giving the object to acquaintances, families, or returning it to its original location. The impulse to rob goods may be lost-arising with the intention of stealing something not for personal benefit, delusion, rage, vengeance, or hatred. Kleptomania sufferers may even steal something from a mate, brother/sister, or acquaintance. While the severity of the need to steal varies, kleptomania sufferers are able to resist attempting fraud when the circumstances do not allow it.

As an example, below are some typical kleptomania symptoms (in both children and adults): (1) Having a deep desire or impulse to take anything that isn't really appropriate. (2) Before and after the process of picking up other people's things, there is a sense of anticipation and excitement. (3) After taking someone else's things, you can feel relaxed, relieved, and fulfilled. (4) Embarrassment, remorse, or fear of being discovered as a cheat. In certain circumstances, though, kleptomania sufferers feel bad and regretful after cheating.

\section{Causes of Kleptomania}

About all children feel the need to obtain things that are not theirs during their development time. At the age of 4-5 years, children develop the practice of stealing items that do not belong to them. Children can have to establish rules and not take other people's possessions until they reach a certain level where they learn spiritual and personal beliefs. Kleptomania disorder, on the other hand, may affect certain adolescents. Kleptomania's precise origin remains unclear. Family background and other mental health conditions may render an individual susceptible to kleptomania (Grant et al., 2020; Goldman, 1992). Kleptomania is most likely to include those in the core families, such as parents and relatives, who have kleptomania, obsessive compulsive disorder (OCD), or substance and alcohol misuse. For fear of being imprisoned, often kleptomania sufferers should not pursue treatment. Kleptomania, on the other hand, may trigger social, family, employment, legal, and financial difficulties if not treated promptly. Other behavioral health conditions such as opioid and alcohol dependence, behavior disorders, eating 
disorders, depression, anxiety, and even attempted suicide can result if kleptomania disease is left untreated (Weintraub et al., 2014). The exact cause of kleptomania remains unknown at this time. However, some reports claim that the following factors contribute to kleptomania.

\section{Chemical Abnormalities in the Brain}

Kleptomania sufferers are thought to have poor serotonin levels, resulting in a deep tendency to rob that they are unable to control, according to several reports. As he is compelled to cheat, he can feel tense. When he steals, the anxiety dissipates, and a sense of joy, relaxation, and happiness replaces it. These emotions are what drive an individual to engage in kleptomania over and over again.

\section{Never Had a Head Injury}

According to an analysis, kleptomania may even be encountered by anyone who has a head wound, but further research is required. Changes in brain performance and drugs that operate in it are believed to be triggered by the wound, which may impair a person's ability to cheat.

According to Durst et al. (2001) there are some of the symptoms of kleptomania (1) The irresistible desire to steal. It can be done in crowded locations such as supermarkets or shops, or in private places such as the homes of friends or relatives; (2) before stealing, kleptomania sufferers feel an increased tension; (3) Feel relief or pleasure after stealing. At the same time feel shame, guilt, regret, hate for yourself, or fear of being arrested; (4) often stolen goods are placed, stored, or given again to others. Not infrequently, the stolen goods are returned to the owner secretly; (5) the desire to steal in kleptomania sufferers can disappear arising. Sufferers also sometimes feel caught up in the urge to steal and repeated acts of theft; (6) Theft by kleptomania sufferers is not based on hallucination, delusions, anger, or revenge.

Kleptomania affects more women than men, and the majority of cases begin in adolescence. The precise cause of this disorder remains unknown, although it is believed to be linked to hereditary causes and a disturbance of the brain's hormonal equilibrium, specifically the hormones serotonin and dopamine. Kleptomania sufferers also have co-occurring psychological conditions such as stress, excessive fear, behavioral disorders, attitude disorders, and eating disorders.

\section{Overcoming Kleptomania with Therapy}

If left unchecked, kleptomania has the ability to ruin people's lives. Emotional issues, jobs, families, and court disputes, for example. This emotion appears when an individual learns that his acts are unethical and illegal.

Kleptomania also leads to health problems (such as fear, bipolar disorder, personality disorder, and depression), substance addiction, and sometimes suicide attempts.

Here are several suggestions for dealing with kleptomania in children: (1) Congratulate the kid as he or she does the best thing. Explain why the acts they took were inappropriate, and require the kid to retrieve the items he took. Praise your child after he or she has completed the task. (2) Request that your child apologize to the individual whose property he has removed, and that he return or compensate for it if your child has ruined it. This will serve as a deterrent to the boy. (3) If your kid does not exhibit a sense of kapok in both of the above cases, send him or her to a psychological doctor right away. (4) Explain to the child that professional assistance will help them lessen their need to take and enjoy a life free of dependence and guilt. 


\section{Treatment of Kleptomania in Children}

\section{Talk to the doctor}

Talking to the doctor is the first step you can take to help deal with kleptomania in your child. Usually, some doctors will advise your child to do Behavior Modification therapy. This therapy is done to determine the right reason behind your child's kleptomania behavior and to perform treatments to improve your child's behavior.

\section{Give the child attention and affection}

In order for your child not to feel anxious and lose confidence, mother needs to always be by her side to provide support. Also try not to act hard because it can add to your child's emotional burden.

\section{Involve the child in physical activities}

To distract the little one from the desire to steal, mother can invite him to do physical activities such as exercising, soaping, cycling, and so on.

\section{Drug Consumption}

These include drugs to overcome addiction (such as naltrexone, an opioid antagonist) and antidepressants (such as fluoxetine, fluvoxamine, paroxetine). The drug is expected to better control its impulsive behavior, resulting in a reduced tendency to steal.

\section{Psychotherapy}

CBT (cognitive behavioral therapy) is a form of therapy that helps people manage their emotions (CBT). This aids in recognizing and replacing harmful negative desires and habits with better, more optimistic alternatives. The following methods are usually used in CBT:

Sensitization that occurs under the surface. People are asked to envision themselves in the worst-case scenario, such as being judged by the masses or going to court.

Aversion therapy is a form of psychotherapy that involves avoiding anything anytime an impulse to rob occurs, the patient is instructed to hold his breath in order to create pain and thereby reverse his intentions.

To control the impulse to cheat, systematic desensitization is a calming and self-deprecation therapy.

Kleptomania is a serious psychiatric illness. Kleptomania may be painful for sufferers and their relatives if it is not treated properly. Any kleptomania sufferers are afraid of getting detained and punished because of the disorder's humiliation.

While there is no effective medication that will heal kleptomania, counseling with psychotherapy and medications will help kleptomania sufferers curb their temptation to rob.

The goal of kleptomania treatment is to figure out what's causing the disorder in the first place. Cognitive behavioral treatment, family counseling therapy, psychodynamics, and behavioral adjustment therapy are several of the treatments that may be utilized to treat kleptomania. These therapy will usually be performed alone or in classes.

In addition to medication, a number of medications are administered to kleptomania patients to complement their psychiatric treatment. Fluvoxamine, fluvoxamine, paroxetine, and sertraline are some of the medications included, and they both work by increasing serotonin levels in the brain. Depression is usually treated with these medications. 
The difference between counseling guidance and psychotherapy according to most experts is the view that the difference between counseling guidance and psychotherapy lies in various aspects.

\section{Approach to Providing Assistance}

The approach of a helping in counseling guidance is by providing encouragement (supportive) and reeducation. Supportive can be interpreted as encouraging clients to develop their potential. Re-educational understanding means increased understanding of self, and problems.

\section{Behavioral Therapy}

Behavioral therapy is the application of a variety of techniques and procedures rooted in various theories about learning. It includes the application and systematic principles of learning on changing behavior towards adaptive ways. This approach has contributed significant contributions, both to clinical and educational fields. Based on the theory of learning, behavioral modification and behavioral therapy are approaches to counseling and psychotherapy dealing with behavior change.

\section{Emotive Rational Therapy}

Emotive rational therapy is a flow of psychotherapy based on the assumption that humans are born with potential, both for rational and honest thinking and for irrational and evil thinking (Ellis, 2002; Ellis, 1999; Robertson, 2019). People have tendencies to nurture themselves, be happy, think and say, love, join others, and grow and actualize themselves. But man also has a tendency towards self-destruction, avoiding thought, slowing down, regretting endless mistakes, superstition, intolerance, perfectionism and self-deprecating, and avoiding growth and self-actualization. Humans also tend to be fixated on old dysfunctional behavior patterns and look for ways to engage in self-sabotage.

\section{Conclusion}

Kleptomania is a disorder that influences children's and families' social lives. The failure to avoid persistent incitement to steal things that are not currently used for personal use or robbed is not due to the item's price being high or low. Any facts regarding kleptomania sufferers include having extreme desires to rob other people's possessions, experiencing intense turmoil while trying to steal, experiencing pleasure when stealing, and experiencing remorse and shame after stealing. Kleptomania patients suffer from paranoia, bipolar illness, behavioral problems, and depression, as well as substance addiction and attempted suicide. As a result, it is important to take steps before things worsen by implementing handlers as soon as possible. The first move in solving kleptomania is the parent's approach to the infant, which can be followed by specialist doctor counseling. So that the kid will exist in harmony and free of psychic disturbances.

\section{References}

Durst, R., Katz, G., Teitelbaum, A., Zislin, J., \& Dannon, P. N. (2001). Kleptomania. CNS drugs, 15(3), 185-195.

Ellis, A. (1999). Why rational-emotive therapy to rational emotive behavior therapy?. Psychotherapy: Theory, Research, Practice, Training, 36(2), 154.

Ellis, A. (2002). Overcoming resistance: A rational emotive behavior therapy integrated approach. Springer Publishing Company.

Fishbain, D. A. (1987). Kleptomania as risk-taking behavior in response to depression. American journal of psychotherapy, 41(4), 598-603. 
Goldman, M. J. (1992). Kleptomania: an overview. Psychiatric Annals, 22(2), 68-71.

Grant, J. E., \& Chamberlain, S. R. (2020). Family history of substance use disorders: Significance for mental health in young adults who gamble. Journal of behavioral addictions, 9(2), 289-297.

Robertson, D. (2019). The philosophy of cognitive-behavioural therapy (CBT): Stoic philosophy as rational and cognitive psychotherapy. Routledge.

Sarasalo, E., Bergman, B., \& Toth, J. (1997). Kleptomania-like behaviour and psychosocial characteristics among shoplifters. Legal and Criminological Psychology, 2(1), 1-10.

Sulthana, N., Singh, M., \& Vijaya, K. (2015). Kleptomania-the Compulsion to Steal. Am. J. Pharm. Tech. Res, 5(3).

Urso, S., Bersani, G., Roma, P., \& Rinaldi, R. (2018). Changes in impulse control disorder features in a present kleptomania patient and importance of rational treatment strategy on social dangerousness: a case report. Journal of Psychopathology, 24(1), 31-36.

Weintraub, P., Dunn, T. M., \& Yager, J. (2014). Relationship of Behavioral Addictions to Eating Disorders and Substance Use Disorders. In Eating Disorders, Addictions and Substance Use Disorders (pp. 405-428). Springer, Berlin, Heidelberg.

Wiedemann, G. (1998). Kleptomania: characteristics of 12 cases. European psychiatry, 13(2), 67-77. 